\title{
Comparative Evaluation of Mechanical Properties of Dental Nanomaterials
}

\author{
Cem Peskersoy ${ }^{1}$ and Osman Culha ${ }^{2}$ \\ ${ }^{1}$ Department of Restorative Dentistry, Ege University Faculty of Dentistry, Izmir, Turkey \\ ${ }^{2}$ Department of Metallurgy and Materials Engineering, Celal Bayar University Faculty of Engineering, Manisa, Turkey
}

Correspondence should be addressed to Cem Peskersoy; dtcempeskersoy@hotmail.com

Received 23 September 2016; Accepted 12 December 2016; Published 7 February 2017

Academic Editor: Ping Xiao

Copyright ( 2017 Cem Peskersoy and Osman Culha. This is an open access article distributed under the Creative Commons Attribution License, which permits unrestricted use, distribution, and reproduction in any medium, provided the original work is properly cited.

\begin{abstract}
This study examines the properties of nanobased dental restorative materials with nanoindentation method in a precise, repeatable, and comparable way. Microhybrid and nanohybrid composites, conventional glass ionomer materials, and light cured nanoionomer materials were utilised for the study. Specimen discs $(r=10 \mathrm{~mm}, h=2 \mathrm{~mm})$ were prepared to test the hardness, modulus of elasticity, yield strength, and fracture toughness values for each sample in a nanoindentation device with an atomic force microscopy addon $(n=25)$. Comparative analyses were performed by one-way ANOVA and post hoc Tukey tests. The hardness and modulus of elasticity values of nanocomposite were higher $(2.58 \mathrm{GPa}$ and $32.86 \mathrm{GPa}$, resp.) than those of other dental materials. Although glass ionomer exhibited a hardness that was similar to a nanoionomer $(0.81$ versus $0.87 \mathrm{GPa})$, glass ionomer had the lowest fracture toughness value $\left(K_{c}=0.83 \mathrm{MPa} / \mathrm{mm}^{0.5}\right)$. The mechanical properties of resin composites improve with additional nanoscale fillers, unlike the glass ionomer material.
\end{abstract}

\section{Introduction}

The success of dental treatments depends not only on biological, chemical, physical, and pathophysiological principles but also on the sufficient and precise knowledge of the mechanical properties of dental tissues and materials. The assessment of the mechanical properties of dental tissues and materials is vital for developing biocompatible dental materials used in dentistry [1]. For the past six decades, multivarious mechanical and physical tests have been performed to measure the mechanical properties of dental materials such as the compressive, tensile, bending, scratch shear strength, and microindentation test [2] (Table 1). Considering the results of a literature review, it is difficult to establish a correlation among such studies because of the different test parameters and the lack of standardisation [3]. Moreover, conventional methods are inappropriate for determining the bulk properties of biphasic materials such as dental resin composites [4]. The filler particles used in these materials are dispersed inhomogeneously, and the measurements performed with a macrotip/microtip most likely measure mechanical properties that differ with measurement. However, measurements of dental materials using a nanoindentation system are relatively nondestructive, and the specimen preparation is less time consuming and, more importantly, allows the simultaneous comparison and evaluation of different variables and properties of different materials [5-7]. Furthermore, with appropriate add-ons and software applications, it is possible to calculate substantial properties such as recovery rate and yield strength, which are difficult to determine with conventional methods $[8,9]$.

Elastic modulus (E) and hardness $(H)$ are the two mechanical properties that are most commonly measured using indentation techniques [10]. Hardness is the resistance of a material to indentation or penetration. It has been used to predict the wear resistance of a material against applied forces such as occlusal loading [11, 12]. Elastic modulus describes the relative stiffness of a material and the ability to stretch under constant loading without deformation [11, 12]. Hence, knowledge of the modulus of elasticity and hardness is 
TABLE 1: Summary of mechanical properties based on nanoindentation tests from various publications.

\begin{tabular}{|c|c|c|c|c|c|c|}
\hline Authors & Specimen & Load & $\begin{array}{c}\text { Hardness } \\
\text { GPa }\end{array}$ & $\begin{array}{l}\text { Young modulus } \\
(\mathrm{GPa})\end{array}$ & $\begin{array}{l}\text { Yield strength } \\
\qquad(\mathrm{GPa})\end{array}$ & $\begin{array}{l}\text { Fracture toughness } \\
\qquad\left(\mathrm{MPa} / \sqrt{ } \mathrm{m}^{2}\right)\end{array}$ \\
\hline Drummond & Composite & $1 \mathrm{mN}$ & $1.2 \pm 0.1$ & $16.0 \pm 1.1$ & - & - \\
\hline Hosseinalipour et al. & Composite & $1 \mathrm{kN}$ & $0.51 \pm 0.1$ & - & - & $1.07 \pm 0.1$ \\
\hline Haik et al. & Composite & $10 \mathrm{mN}$ & $0.8 \pm 0.2$ & $15.7 \pm 1.7$ & $0.05 \pm 0.01$ & - \\
\hline Salerno et al. & Composite & $10 \mathrm{mN}$ & $0.5 \pm 0.1$ & $10.8 \pm 4.3$ & $0.03 \pm 0.005$ & $0.42 \pm 0.1$ \\
\hline El-Safty et al. & Composite & $10 \mathrm{mN}$ & $1.2 \pm 0.4$ & $19.2+4.9$ & $0.07 \pm 0.01$ & - \\
\hline Mohamad et al. & Composite & $0.2 \mathrm{mN}$ & $1.4 \pm 0.2$ & $19.9 \pm 1.6$ & $0.09 \pm 0.01$ & - \\
\hline Hamouda & Nanocomposite & $10 \mathrm{mN}$ & $0.1 \pm 0.01$ & - & - & $0.62 \pm 0.07$ \\
\hline Curtis et al. & Nanocomposite & $20 \mathrm{mN}$ & $0.2 \pm 0.02$ & $8.7 \pm 1.9$ & - & - \\
\hline Karimzadeh et al. & Nanocomposite & $7.5 \mathrm{mN}$ & $0.5 \pm 0.05$ & $15 \pm 0.9$ & - & - \\
\hline Rosa et al. & Nanocomposite & $100 \mathrm{mN}$ & $0.2 \pm 0.01$ & $8.5 \pm 2.0$ & $0.01 \pm 0.003$ & - \\
\hline Wang et al. & Glass Ionomer & $10 \mathrm{mN}$ & $0.6 \pm 0.1$ & $10.4 \pm 1.3$ & - & - \\
\hline Xie et al. & Glass Ionomer & $100 \mathrm{mN}$ & $0.7 \pm 0.02$ & $4.5 \pm 0.3$ & $0.05 \pm 0.02$ & - \\
\hline Farahat et al. & Nano-ionomer & $5 \mathrm{mN}$ & $0.8 \pm 0.06$ & $11.45 \pm 1.5$ & - & $0.75 \pm 0.1$ \\
\hline
\end{tabular}

important for understanding the clinical behavior of many biomaterials.

In the field of restorative dentistry and dental materials, nanotechnology has become one of the widest applications in the manufacturing of biocompatible materials [13-15]. Increasing mechanical properties with nanoingredients has resulted in advanced restorative materials called nanocomposites and nanoionomers [16, 17]. Nanobased restorative materials are mostly reinforced and refurbished resin composite materials that consist of an organic resin matrix, silane coupling agents, and inorganic micro- and nanofiller particles [16-18]. Nanofillers in resin composites and nanoionomers were found to be more effective at reducing polymerisation shrinkage, decreasing wear, and improving a material's mechanical properties compared with micro- and macrofillers $[19,20]$. Increasing the filler rate is indirectly related to hardness, rigidity, elasticity, and toughness [21]. Nanosized filler particles can provide substantial improvements in the resin composite hardness, and elasticity has a tremendous effect on both the optical properties of materials and durability. In addition, the nanosized particles are involved in the fracture mechanisms of the resin composites, including particle bridging, debonding at the poles of the particle/matrix interface, and crack deflection around the particles, which interact directly with the mechanical properties [22]. Besides, increased stiffness in nanomaterials has a minor negative effect on the materials' polishability and surface roughness [23].

The aim of the present study was to investigate and evaluate the mechanical properties of nanobased dental materials in comparison with conventional restorative materials with the indentation test on the nanometer scale. Our null hypothesis is that both the nanocomposite and nanoionomer exhibit improved mechanical properties compared with the conventional resin composite and glass ionomer.

\section{Materials and Methods}

2.1. Specimen Preparation. The dental composite materials evaluated in the current investigation have been selected to compare the conventional composites to available nanocomposites. Based on previous studies, four materials from the same manufacturer (3M ESPE) have been selected for the study: universal microhybrid resin composite (Filtek Z250, 3M ESPE, St Paul, MN, USA) and glass ionomer (Ketac Cem, 3M ESPE, St Paul, MN, USA) were selected for comparison to nanohybrid resin composite (Filtek Z550, 3M ESPE, St Paul, MN, USA) and nanoionomer (Ketac Nano, 3M ESPE, St Paul, MN, USA) (Table 2). As the materials vary widely in their filler and resin content, the measured mechanical properties exhibit a wide range of values to facilitate comparison and statistical analysis, whereas nanocomposite belongs to the class of nanohybrid composite materials that include nanofillers $(20 \mathrm{~nm})$ and microfillers $(0.2 \mu \mathrm{m}-1 \mu \mathrm{m})$. Fillers are zirconia/ silica, with $82 \%$ loading by volume [24]; the content of the nanoionomer system consists of an acid-reactive fluoroaluminosilicate glass (FAS) and contains a combination of nanofillers and nanoclusters [25]. Ten circle specimens of each dental material were built up to $\sim 10 \mathrm{~mm}$ in diameter and $\sim 2.0 \mathrm{~mm}$ in thickness. Glass ionomers were mixed for 30 seconds according to the manufacturer's instructions and bulked into a Teflon hollow matrix as well as composites [26]. A flat glass piece was applied gently to compress and allow the removal of the excess material. Composites and nanoionomers were cured with LED lamp for 40 seconds $(1000 \mathrm{~mW} / \mathrm{s}, 440-480 \mathrm{~nm})$ (Bluephase, Ivoclar Vivadent, Liectenstein) while the conventional glass ionomer was not (approx. $11 \mathrm{~min}$ ) until the final setting is completed. Composite and nanoionomers were stored for 48 hours until final polymerisation was completed. The specimens were handground polished on silicon carbide paper under current water flow to achieve flat and parallel surfaces $[3,27]$. 
TABLE 2: Characteristics of selected materials according to material MSDS.

\begin{tabular}{|c|c|c|c|c|c|}
\hline $\begin{array}{l}\text { Material name } \\
\& \text { manufacturer }\end{array}$ & Batch number & Material type & Matrix type & Filler type & Loading\% \\
\hline $\begin{array}{l}\text { Filtek Z550 } \\
(\mathrm{NC})\end{array}$ & N333352 & $\begin{array}{l}\text { Nanohybrid } \\
\text { resin composite }\end{array}$ & $\begin{array}{l}\text { BIS-GMA, UDMA, } \\
\text { BIS-EMA, EGDMA, } \\
\text { TEGDMA }\end{array}$ & $\begin{array}{c}\text { Surface-modified zirconia/silica } \\
\text { Nonagglomerated } \\
\text { surface-modified silica }\end{array}$ & (82\%wt) \\
\hline $\begin{array}{l}\text { Filtek Z250 } \\
(\text { MRC) }\end{array}$ & $6020 A 3$ & $\begin{array}{l}\text { Microhybrid } \\
\text { resin composite }\end{array}$ & $\begin{array}{l}\text { BIS-GMA, TEGDMA, } \\
\text { UDMA, functionalised } \\
\text { dimethacrylate }\end{array}$ & Zirconia/silica & (76\% wt) \\
\hline $\begin{array}{l}\text { Ketac Nano } \\
(\mathrm{NI})\end{array}$ & 20081024 & Nanoionomer & $\begin{array}{l}\text { PEGDMA, HEMA } \\
\text { BİS-GMA, TEGDMA }\end{array}$ & $\begin{array}{l}\text { Silane treated glass } \\
\text { Silane treated zirconia } \\
\text { Silane treated silica } \\
\text { Glass powder }\end{array}$ & (85-90\% wt) \\
\hline $\begin{array}{l}\text { Ketac Cem } \\
\text { (GIC) }\end{array}$ & 394699 & Glass ionomer & $\begin{array}{c}\text { Copolymer of } \\
\text { Acrylic/Maleic Acid }\end{array}$ & Glass powder & $(80-90 \% \mathrm{wt})$ \\
\hline
\end{tabular}

2.2. AFM Nanoindentation Test. The indentation experiments were performed using an atomic force microscopy Ambios Q250 (Ambios, Moscow, Russia) system combined with the IBIS depth sensing nanoindentation system (Fischer-Cripps Laboratories Pty Ltd., Sydney, Australia). A Berkovich indenter, calibrated for the materials, was employed with a stable loading at the lowest speed $(0.061 \mathrm{mN} / \mathrm{sec})$. This indenter consists of a three-sided pyramidal diamond tip (Young's modulus: $1140 \mathrm{GPa}$ ) with an apex angle of $66^{\circ}$. The test was conducted in a dry environment and constant temperature $\left(25^{\circ} \mathrm{C}\right)$ within an insulated glass cabinet that was isolated from thermal and physical factors [27]. While three indentation points were taken on each specimen in total, 75 measurements were carried out [27]. Closed loop loading and unloading with 10 data points for each of these parts and a maximum force of $20 \mathrm{mN}$ were used $[9,28]$. In every indentation step, nanohardness, Young modulus, and indentation depth values were acquired. Nanohardness $(H)$ is defined as the maximum load, $P_{\max }(\mathrm{mN})$, divided by the projected area of the contact impression, $A_{c}(1)$, and Young's modulus $(E)$ was calculated from (2):

$$
\begin{gathered}
H=\frac{P}{A_{c}}=\frac{P_{\max }}{k_{c} \cdot h_{c}{ }^{2}}, \\
E=\frac{\sigma}{\varepsilon}, \\
E=\frac{F / A}{\Delta l / L_{0}}, \\
E=\frac{1-v^{2}}{1 / E_{r}-\left(1-v_{i}^{2}\right) / E_{i}},
\end{gathered}
$$

where $k_{c}$ is the constant of the device; $h_{c}$ is the indentation depth $(\mathrm{mm}) ; E_{r}$ is the reduced elasticity; and $v$ - $v_{i}$ are the Poisson ratios of the test material and indenter [29].

The nanoindentation system software uses $\mathrm{C}++$ nanoindentation algorithms that are developed to calculate the yield strength and fracture toughness [9]. Therefore, calculations of the indentation yield point $\left(\vartheta_{y}\right)$ according to the correlation between hardness and modulus (3) and fracture toughness $\left(K_{c}\right)$ according to formula (4) have been performed:

$$
\begin{gathered}
Y\left(\vartheta_{y}\right)=7 \cdot 10^{-2} H-4.4 \cdot 10^{-4} E, \\
K_{c}=0.0084 \cdot\left(\frac{E}{H}\right)^{0.4} \cdot\left(\frac{2 P}{l}\right) \cdot\left(\frac{1}{c^{0.5}}\right),
\end{gathered}
$$

where 0.0084 is the indentation constant; $l$ is average diagonal length $(\mathrm{mm})$, and $c$ is crack length $(\mathrm{mm})$ [30]. The effect of filler content and distribution of the materials were analysed with the AFM investigations by determining 10 different film areas of $40 \times 40 \mu \mathrm{m}$ with a resolution of 512 pixels. The AFM images of the materials were also acquired to evaluate the surface roughness and filler/matrix interaction.

2.3. Statistical Analysis. The results are expressed as the mean \pm standard deviation. The normal distribution of each dataset was confirmed using the Kolmogorov-Smirnov test. Intragroup data regarding the hardness, Young modulus, yield strength, and fracture toughness values were analysed by Mann-Whitney $U$ test, and analyses among the groups were based on one-way variance test (ANOVA) followed by a post hoc Tukey test with the SPSS 22.0 software (IBM, New York, NY, USA) $(p=0.01)$.

\section{Results}

In the present study, the nanohardness and Young modulus, yield strength, and fracture toughness values were determined and compared (Table 3). AFM images were also obtained for the 4 different study groups: (G1) nanocomposite (NC); (G2) microhybrid resin composite (MRC); (G3) nanoionomer (NI); and (G4) conventional glass ionomer materials (GIC).

3.1. Nanohardness and Young Modulus Values. Nanohardness $(H)$ and Young modulus $(E)$ were measured in the loaddisplacement curve based on the aim of the unloading curve according to the Oliver-Pharr method [10, 31] (Figure 1). The average nanohardness and Young modulus values measured 
TABLE 3: Nanomechanical properties of the study groups.

\begin{tabular}{lcccc}
\hline & $\begin{array}{c}\text { Nanohardness } \\
(\mathrm{GPa})\end{array}$ & $\begin{array}{c}\text { Elasticity modulus } \\
(\mathrm{GPa})\end{array}$ & $\begin{array}{c}\text { Yield point } \\
(\mathrm{GPa})\end{array}$ & $\begin{array}{c}\text { Fracture toughness } \\
\left(\mathrm{MPa} / \mathrm{m}^{0.5}\right)\end{array}$ \\
\hline Nanocomposite (NC) & $2.58(0.16)$ & $32.86(1.47)$ & $0.17(0.01)$ & $1.75(0.11)$ \\
Microhybrid composite (MRC) & $1.84(0.16)$ & $22.65(1.47)$ & $0.11(0.01)$ & $1.52(0.08)$ \\
Nanoionomer (NI) & $0.87^{\dagger}(0.10)$ & $16.31(1.08)$ & $0.06^{\dagger}(0.01)$ & $1.27(0.06)$ \\
Conventional glass ionomer (GIC) & $0.81^{\dagger}(0.09)$ & $13.45(1.01)$ & $0.05^{\dagger}(0.01)$ & $0.83(0.08)$ \\
\hline
\end{tabular}

(i) The number in parentheses indicates the standard deviation $( \pm)$.

(ii) The same superscripts indicate differences that were statistically insignificant $(p>0.01)$.

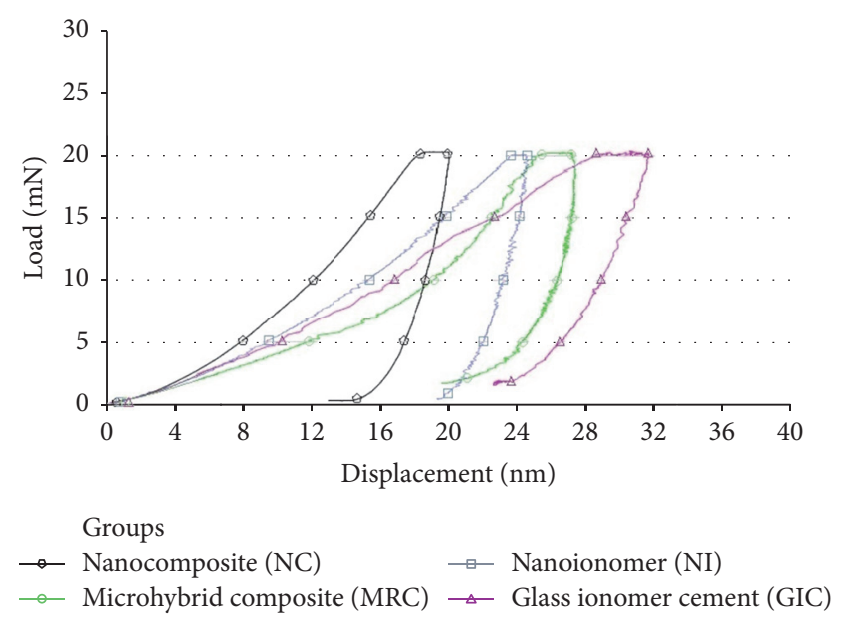

FIGURE 1: Load-displacement plots of four study groups obtained from different force steps. Regular load-unload curves of NC presented in the plot prove the well-composed and uniform composition of the material.

from the NC, MRC, NI, and GIC are presented in Table 3. Consistent with these measurements, though the nanoionomer and glass ionomer have similar hardness $(p>0.01)$, the other groups differ from each other $(p<0.01)$. The average Young moduli $(E)$ of the specimens were $32.86 \mathrm{GPa}$ and 22.65 $\mathrm{GPa}$ for $\mathrm{NC}$ and $\mathrm{MRC}$, respectively, and $16.31 \mathrm{GPa}$ and $13.45 \mathrm{GPa}$ for the NI and GIC groups, respectively. The differences between each of the study groups were found to be statistically significant $(p<0.01)$.

3.2. Yield Strength and Fracture Toughness. Yield strength corresponds to the point at which material deforms only elastically under the applied stress. Once this point is passed, nonreversible deformation occurs until the fracture point (toughness). In the present study, both the yield strength and fracture toughness of NC were the highest among the groups $\left(\vartheta_{n}=0.17 \pm 0.01 \mathrm{GPa}, K_{c}=1.75 \pm 0.11 \mathrm{MPa}\right)(p<$ 0.01 ). Though NI and GIC exhibited similar yield points, the fracture toughness of NI was significantly different from that of MRC $(p<0.01)$.

3.3. AFM and SEM Observations of the Indentations. The AFM micrographs and SEM figures of the indented specimen surfaces are shown in Figures 2(a)-2(1). SEM images of the different composites and ionomers represent the surface morphology and the effect of the nonagglomerated surfacemodified silica particles on the hardness and fracture toughness. The AFM images of all indentation tests were examined to evaluate if any radial crack around the indentation point was observed during the indentation tests. Cracking around the hole will cause modulus and hardness results measured from nanoindentation tests which will not be reliable, because, in this case, a large fraction of the force applied to the indenter is consumed for the formation and growth of cracks instead of material deformation [32].

The images showed that although there were different materials tested in the study with different composition and structure, glass ionomers with/without filler ingredient still had the same surface roughness (Figures $2(\mathrm{~g})$ and $2(\mathrm{j})$ ), while nanocomposite presented smooth and well-composed surface morphology compared to the composite resin after finishing and polishing procedure (Figures 2(a), 2(d), 2(c), and $2(\mathrm{f}))$. Although nanoscale filler insertion in nanoionomer increased the hardness of the material, it has been proven that the yield strength and fracture resistance were the main factors affecting the microcracks caused by the indentation force (Figures 2(i) and 2(l)).

\section{Discussion}

Nanotechnology leads to the production of smaller filler particles for resin composites with an average size of $50 \mathrm{~nm}$, unlike milling procedures. However, inserting nanosized particles into the load of the inorganic phase in $80 \mathrm{wt} \%$ compared to conventional restoratives (50-70 wt \%) improved the wear resistance and integrity of the resin composites and ionomers $[33,34]$. Though it has been proven that nanosized filler particles provide substantial improvements in material toughness, it is still not clear how nanosized particles affect the elasticity and hardness of dental restorative materials [22-35].

The current study aimed to determine the mechanical properties of dental nanomaterials using the nanoindentation method and compared them to evaluate their compliance. Thus, this research was conducted to include determination of four basic mechanical properties of two nanobased dental restorative materials compared to the conventional replacements: nanohardness, elastic moduli, yield strength, and fracture toughness. According to the results of the nanoindentation tests, insertion of nanoscale fillers into both dental resins and ionomers resulted in improved hardness, elasticity, and 


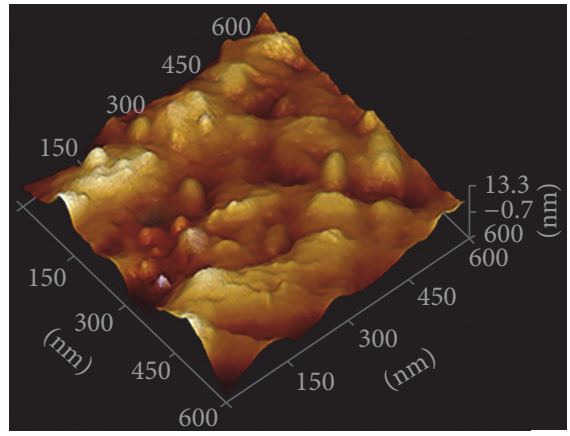

(a)

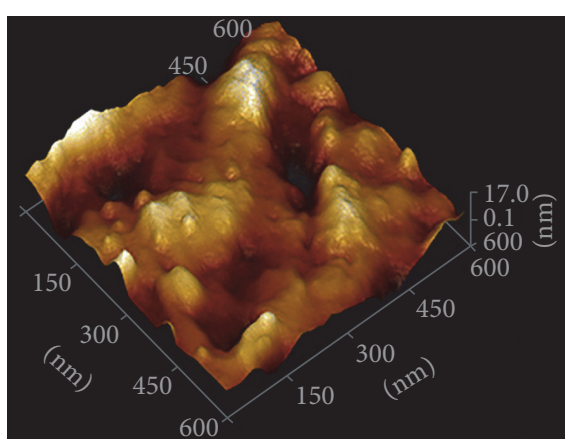

(d)

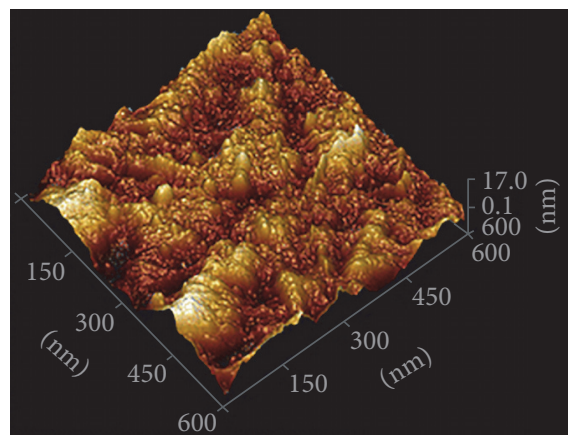

(g)

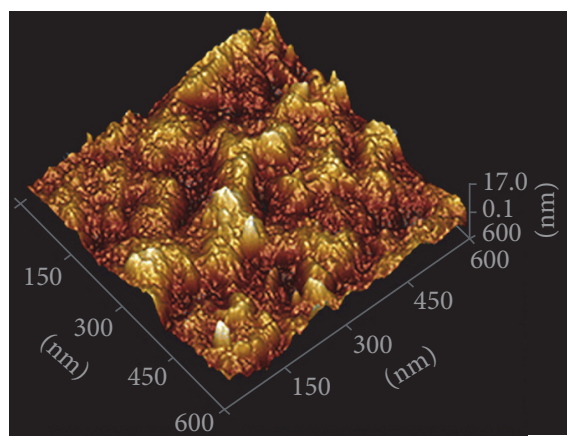

(j)

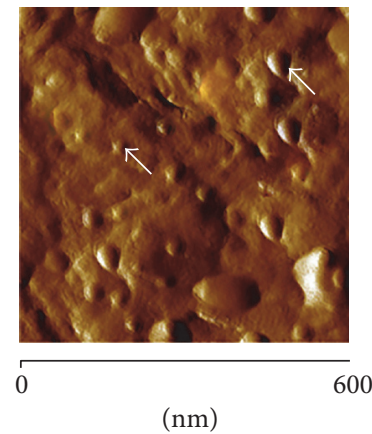

(b)

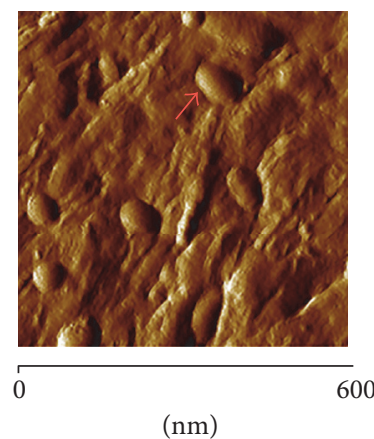

(e)

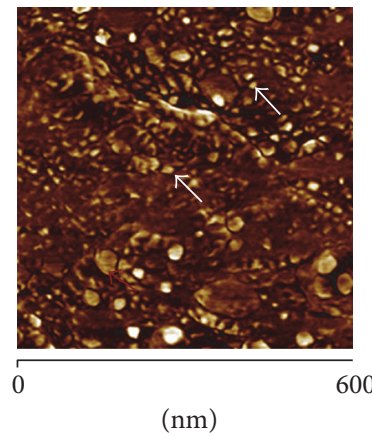

(h)

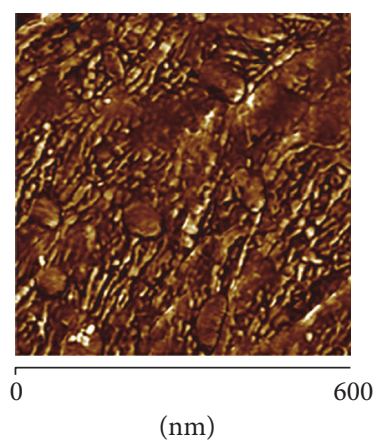

(k)

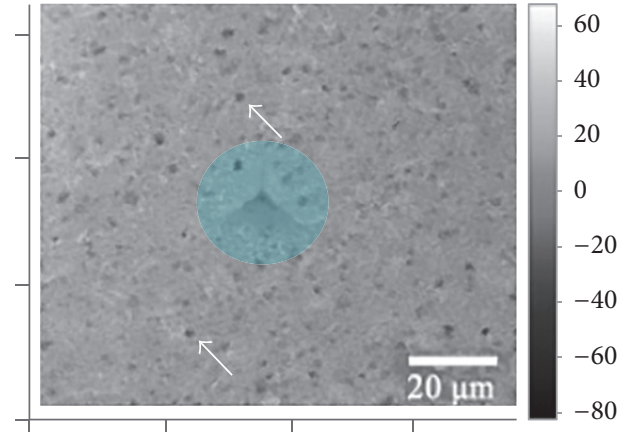

(c)

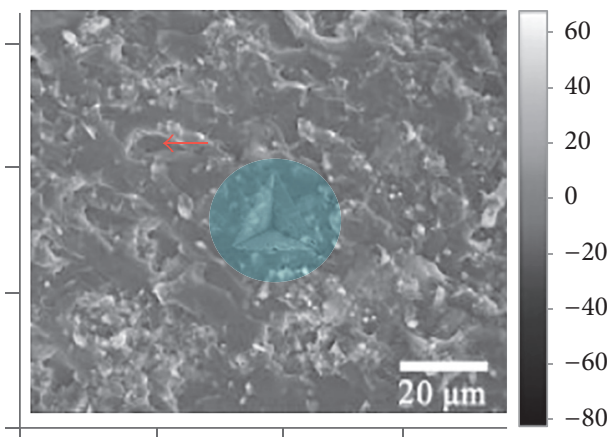

(f)

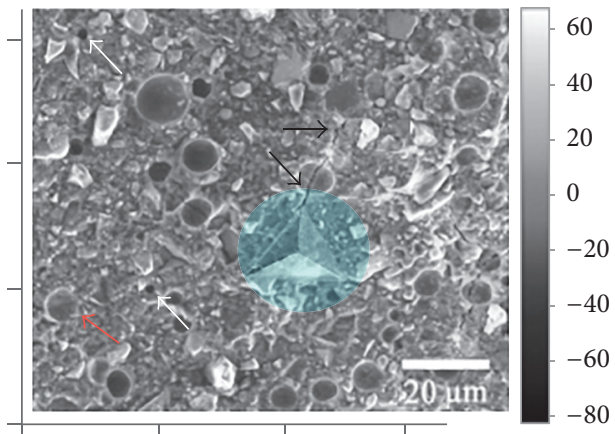

(i)

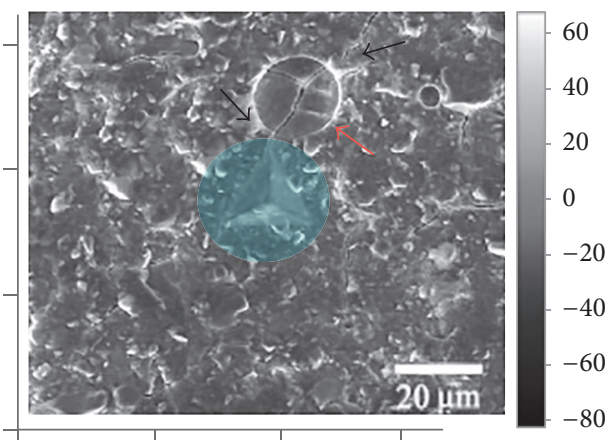

(1)

FIGURE 2: AFM and SEM images of the four study groups. While nanoscale and microfillers were shown with white and red markers, microfracture and indentation area were presented with black markers and blue circle. 
toughness. These findings are consistent with the previous studies, which showed that the filler content significantly interfered with the mechanical properties of the materials $[36,37]$. Therefore, our null hypothesis was confirmed.

The compatibility of the nanohardness and fracture resistance of the dental materials used for posterior restorations under constant masticatory stresses affects both the related tooth and the antagonist tooth directly $[32,38]$. Occlusal wear and fracture incidence generally depend on the selected restorative materials' indentation hardness and fracture toughness $[38,39]$. In our study, both hardness and fracture toughness improved for nanocomposites and ionomers due to the increased filler loading and nanosized particle ingredients. The majority of studies are in general agreement that the fracture toughness of composites increases as filler volume fraction is increased [30,34]. In general, it was shown that fracture toughness was highest in the more heavily filled resins being also independent of degree of conversion in the matrix. An in vitro study conducted by Ilie et al. focused on the fracture toughness of 69 resin composite and glass ionomer materials has proven that the presence of reinforcing filler particles in resin composites distributes the force into many components and causes the crack front to curve or dissipate between particles [40]. When comparing these results with our findings, resin composite and ionomer materials with nanofiller insert showed similar increased fracture toughness due to their regular distributed uniform shaped filler ingredients.

In this respect, our study was consistent with previous studies in the literature focused on mechanical properties and behaviors of the resin and ionomer materials tested with both conventional and indentational test methods [7, 40-43]. In contrast, the hardness and toughness results ( $\mathrm{GPa}$ ) obtained from this study differ from those recently reported by Rosa and Salerno et al., who found that lower values for both properties could be caused by the applied force and indentation point differences $[33,44]$.

The elastic properties of the restorative materials, such as yield strength and elastic moduli, measure the ability of the materials to restore to their original shape when a load is applied and removed [7]. The modulus of elasticity is directly related to the amount of deformation when the material is subjected to external forces [26, 45]. Hence, dental materials that are used in posterior restorations must possess an adequate modulus, strain, and yield ability to withstand the high forces during mastication [46]. In addition, the percentage of endurance combination, modulus of elasticity, and elastic recovery of the material used in the restoration of abfraction defects, which result from stress accumulation on the edge of tooth enamel-cement with the impact of occlusal forces, should be compatible with that of tooth tissue [47]. Materials with low elasticity modulus deform more under masticatory stresses and do not have sufficient resilience, which may cause catastrophic failure, whereas a high elastic modulus is required to withstand deformation and cuspal fracture [22, 37]. According to the results, the yield and elasticity of the resin composites change markedly as the size of the filler content is reduced and the loading rate is increased. Nevertheless, nanoionomers exhibit similar elastic responses compared to glass ionomers. These findings are consistent with prior studies that show that while resin composites adjust reinforcement with different types of filler insertions, the flexibility of the glass ionomer material mostly depends on the concentration of the composition, the manufacturing, and setting process $[26,41,48]$.

The AFM analysis performed to determine the indentation point and possible radial cracks that can cause the force to be consumed by the formation of the crack and prevent the deformation of the material to measure the yield and fracture toughness values $[32,49,50]$.

In addition, measuring the proper mechanical and physical properties of the restorative dental materials is important for both material selection and the clinical performance of materials. The nanoindentation test method is superior to conventional test methods in terms of four factors that are the reasons for being preferred by others [31]. First, the load and displacement of the indenter tip are continuously monitored as the probe is applied to the specimen, which enables the calculation of the stress/strain relationship. Second, relatively small amounts of material are required for specimen preparation, and the noninvasive measurement process does not deform the samples prior to further experiments. Third, the test options permit different calculation modes by changing the experimental parameters, such as appropriate indenter tip selection for each material and optimisation of applied load and time. Fourth, associated software allows the calculation and validation of multifarious mechanical properties in a single load-unload test process $[4,27]$. Therefore, these factors should be considered in the selection of restorative materials in clinical practice.

\section{Conclusions}

Nanoindentation is one of the most precise ways of determining and comparing the mechanical properties of restorative materials. However, it was shown that the measurement of resin composites and ionomers in the laboratory is important for predicting the clinical performance of the materials. Although nanoscale particle insertion in resin composites results in improved hardness, elasticity, and toughness values, it has failed to produce the same outcomes for ionomers in contrast to expectations. Chemical composition of the nanoionomers especially the irregular glass particle distribution on the surface of NI, which results in greater amount of acid to react with nanoscale particles, possibly is related to the decrease in mechanical properties of the material in certain areas. Within the limits of this in vitro study, comprehensive tests conducted using the experimental conditions corresponding to the in vivo environment provide useable and comparable information about dental nanomaterials.

\section{Competing Interests}

The authors certify that they have no commercial associations that might represent a conflict of interests. 


\section{Acknowledgments}

This study was supported financially by Ege University (no. 2010DIS015).

\section{References}

[1] J. F. McCabe and A. W. G. Walls, Applied Dental Materials, Blackwell Publishing, Malden, Mass, USA, 2008.

[2] A. Fischer, Handbook of Nanoindentation and Indenter Selection Guidelines, Fischer-Cripps Laboratories Pty. Limited, Sydney, Australia, 2011.

[3] M. L. Oyen, L. H. He, and M. V. Swain, Handbook of Nanoindentation: With Biological Applications, Pan Stanford Publishing, Boca Raton, Fla, USA, 2008.

[4] S. El-Safty, R. Akhtar, N. Silikas, and D. C. Watts, "Nanomechanical properties of dental resin-composites," Dental Materials, vol. 28, no. 12, pp. 1292-1300, 2012.

[5] J. L. Drummond, "Nanoindentation of dental composites," Journal of Biomedical Materials Research Part B: Applied Biomaterials, vol. 78, no. 1, pp. 27-34, 2006.

[6] D. M. Ebenstein and L. A. Pruitt, "Nanoindentation of biological materials," Nano Today, vol. 1, no. 3, pp. 26-33, 2006.

[7] C. S. Meng, Biomechanical characterization of dental composite restoratives-a micro-indentation approach [Ph.D. thesis], University of Singapore, Singapore, 2008.

[8] J. L. Drummond, "Degradation, fatigue, and failure of resin dental composite materials," Journal of Dental Research, vol. 87, no. 8, pp. 710-719, 2008.

[9] M. Toparlı and N. S. Köksal, "Hardness and yield strength of dentin from simulated nano-indentation tests," Computer Methods \& Programs in Biomedicine, vol. 77, no. 3, pp. 253-257, 2005.

[10] W. C. Oliver and G. M. Pharr, "Measurement of hardness and elastic modulus by instrumented indentation: advances in understanding and refinements to methodology," Journal of Materials Research, vol. 19, no. 1, pp. 3-20, 2004.

[11] B. W. Darvell, A Glossary of Terms for Dental Materials Science, Michigan University, 8th edition, 1999.

[12] J. Sabbagh, J. Vreven, and G. Leloup, "Dynamic and static moduli of elasticity of resin-based materials," Dental Materials, vol. 18, no. 1, pp. 64-71, 2002.

[13] R. Chandki, M. Kala, K. N. Kumar, B. Brigit, P. Banthia, and R. Banthia, "Nanodentistry': exploring the beauty of miniature," Journal of Clinical and Experimental Dentistry, vol. 4, pp. 119$124,2012$.

[14] K. D. Jandt and B. W. Sigusch, "Future perspectives of resinbased dental materials," Dental Materials, vol. 25, no. 8, pp. 10011006, 2009.

[15] S. R. Kumar and R. Vijayalakshmi, "Nanotechnology in dentistry," Indian Journal of Dental Research, vol. 17, no. 2, pp. 62-65, 2006.

[16] M.-H. Chen, "Update on dental nanocomposites," Journal of Dental Research, vol. 89, no. 6, pp. 549-560, 2010.

[17] C. M. Killian and T. P. Croll, "Nano-ionomer tooth repair in pediatric dentistry," Pediatric Dentistry, vol. 32, no. 7, pp. 530535,2010

[18] S. B. Mitra, D. Wu, and B. N. Holmes, "An application of nanotechnology in advanced dental materials," Journal of the American Dental Association, vol. 134, no. 10, pp. 1382-1390, 2003.
[19] M.-H. Chen, C.-R. Chen, S.-H. Hsu, S.-P. Sun, and W.-F. Su, "Low shrinkage light curable nanocomposite for dental restorative material," Dental Materials, vol. 22, no. 2, pp. 138-145, 2006.

[20] T. Lainović, M. Vilotić, L. Blažić, D. Kakaš, D. Marković, and A. Ivanišević, "Determination of surface roughness and topography of dental resin-based nanocomposites using AFM analysis," Bosnian Journal of Basic Medical Sciences, vol. 13, no. 1, pp. $34-43,2013$

[21] A. Nalçaci, "Nano-hibrit bir Kompozit rezinin yüzey sertliğinin in vitro olarak incelenmesi," Ankara Üniversitesi Diş Hekimliği Fakültesi Dergisi, vol. 32, no. 2, pp. 91-98, 2005.

[22] K. S. Chan, Y.-D. Lee, D. P. Nicolella, B. R. Furman, S. Wellinghoff, and R. Rawls, "Improving fracture toughness of dental nanocomposites by interface engineering and micromechanics," Engineering Fracture Mechanics, vol. 74, no. 12, pp. 18571871, 2007.

[23] H. M. Barakah and N. M. Taher, "Effect of polishing systems on stain susceptibility and surface roughness of nanocomposite resin material," Journal of Prosthetic Dentistry, vol. 112, no. 3, pp. 625-631, 2014.

[24] A. Ivanišević, T. Lainović, D. Vilotić, L. Blažić, K. Gerić, and M. Vilotić, "Ultimate strength of dental nanomaterials under static loading," Journal for Technology of Plasticity, vol. 38, no. 1, pp. 23-31, 2013.

[25] E. Lihua, M. Irie, N. Nagaoka, T. Yamashiro, and K. Suzuki, "Mechanical properties of a resin-modified glass ionomer cement for luting: effect of adding spherical silica filler," Dental Materials Journal, vol. 29, no. 3, pp. 253-261, 2010.

[26] K. Masouras, R. Akhtar, D. C. Watts, and N. Silikas, "Effect of filler size and shape on local nanoindentation modulus of resincomposites," Journal of Materials Science: Materials in Medicine, vol. 19, no. 12, pp. 3561-3566, 2008.

[27] A. C. Fischer-Cripps, "Critical review of analysis and interpretation of nanoindentation test data," Surface and Coatings Technology, vol. 200, no. 14-15, pp. 4153-4165, 2006.

[28] O. Culha, M. Toparli, S. Sahin, and T. Aksoy, "Characterization and determination of FexB layers' mechanical properties," Journal of Materials Processing Technology, vol. 206, no. 1-3, pp. 231-240, 2008

[29] D. C. Haeberle, The use of nanoindentation to determine composite interfacial shear strength and the effects of environmental aging [Ph.D. thesis], Virginia Polytechnic Institute and State University, 2001.

[30] E. D. Bonilla, M. Yashar, and A. A. Caputo, "Fracture toughness of nine flowable resin composites," The Journal of Prosthetic Dentistry, vol. 89, no. 3, pp. 261-267, 2003.

[31] D. J. Shuman, A. L. M. Costa, and M. S. Andrade, "Calculating the elastic modulus from nanoindentation and microindentation reload curves," Materials Characterization, vol. 58, no. 4, pp. 380-389, 2007.

[32] A. Karimzadeh, M. R. Ayatollahi, and H. A. Shirazi, "Mechanical properties of a dental nano-composite in moist media determined by nano-scale measurement," International Journal of Materials, Mechanics and Manufacturing, pp. 67-72, 2014.

[33] R. S. Rosa, C. A. E. Balbinot, E. Blando et al., "Evaluation of mechanical properties on three nanofilled composites," Stomatologija, Baltic Dental and Maxillofacial Journal, vol. 14, pp. 126130, 2012.

[34] F. Shafiei, M. S. Tavangar, Y. Ghahramani, and Z. Fattah, "Fracture resistance of endodontically treated maxillary premolars restored by silorane-based composite with or without fiber or 
nano-ionomer," Journal of Advanced Prosthodontics, vol. 6, no. 3, pp. 200-206, 2014.

[35] D. Xie, J. Zhao, Y. Yang, J. Park, T. M. Chu, and J. T. Zhang, "Preparation and evaluation of a high-strength biocompatible glass-ionomer cement for improved dental restoratives," Biomedical Materials, vol. 3, no. 2, 2008.

[36] P. Lambrechts, M. Braem, and G. Vanherle, "Evaluation of clinical performance of posterior composite resins and dentin adhesives," Operative Dentistry, vol. 12, pp. 53-78, 1987.

[37] N. C. Lawson and J. O. Burgess, "Wear of nanofilled dental composites at varying filler concentrations," Journal of Biomedical Materials Research-Part B Applied Biomaterials, vol. 103, no. 2, pp. 424-429, 2015.

[38] J. A. Kaidonis, "Tooth wear: the view of the anthropologist," Clinical Oral Investigations, vol. 12, no. 1, pp. 21-26, 2008.

[39] Z. D. Yesil, S. Alapati, W. Johnston, and R. R. Seghi, "Evaluation of the wear resistance of new nanocomposite resin restorative materials," Journal of Prosthetic Dentistry, vol. 99, no. 6, pp. 435443, 2008.

[40] N. Ilie, R. Hickel, A. S. Valceanu, and K. C. Huth, "Fracture toughness of dental restorative materials," Clinical Oral Investigations, vol. 16, no. 2, pp. 489-498, 2012.

[41] M. Z. Shah Khan, G. Simpson, and C. R. Townsend, "A comparison of the mechanical properties in compression of two resin systems," Materials Letters, vol. 52, no. 3, pp. 173-179, 2002.

[42] D. S. Farahat, E. E. S. Al Wakeel, M. F. Othman, and A. A. F. Abdel-Samad, "Creep, fracture toughness and hardness of a nano-ionomer restorative material," Egyptian Dental Journal, vol. 57, pp. 875-881, 2011.

[43] T. Yamazaki, S. R. Schricker, W. A. Brantley, B. M. Culbertson, and W. Johnston, "Viscoelastic behavior and fracture toughness of six glass-ionomer cements," Journal of Prosthetic Dentistry, vol. 96, no. 4, pp. 266-272, 2006.

[44] M. Salerno, N. Patra, and A. Diaspro, "Atomic force microscopy nanoindentation of a dental restorative midifill composite," Dental Materials, vol. 28, no. 2, pp. 197-203, 2012.

[45] S. A. Rodrigues Jr., C. H. Zanchi, R. V. de Carvalho, and F. F. Demarco, "Flexural strength and modulus of elasticity of different types of resin-based composites," Brazilian Oral Research, vol. 21, no. 1, pp. 16-21, 2007.

[46] L. H. He and M. V. Swain, "Nanoindentation derived stressstrain properties of dental materials," Dental Materials, vol. 23, no. 7, pp. 814-821, 2007.

[47] B. van Meerbeek, G. Willems, P. Lambrechts et al., "Assessment by nano-indentation of the hardness and elasticity of the resindentin bonding area," Journal of Dental Research, vol. 72, no. 10, pp. 1434-1442, 1993.

[48] H. Takahashi, W. J. Finger, T. Endo et al., "Comparative evaluation of mechanical characteristics of nanofiller containing resin composites," American Journal of Dentistry, vol. 24, no. 5, pp. 264-270, 2011.

[49] S. Thorat, N. Patra, R. Ruffilli, A. Diaspro, and M. Salerno, "Preparation and characterization of a BisGMA-resin dental restorative composites with glass, silica and titania fillers," Dental Materials Journal, vol. 31, no. 4, pp. 635-644, 2012.

[50] S. Sauro, R. Osorio, T. F. Watson, and M. Toledano, "Assessment of the quality of resin-dentin bonded interfaces: an AFM nanoindentation, $\mu \mathrm{tBS}$ and confocal ultramorphology study," Dental Materials, vol. 28, no. 6, pp. 622-631, 2012. 

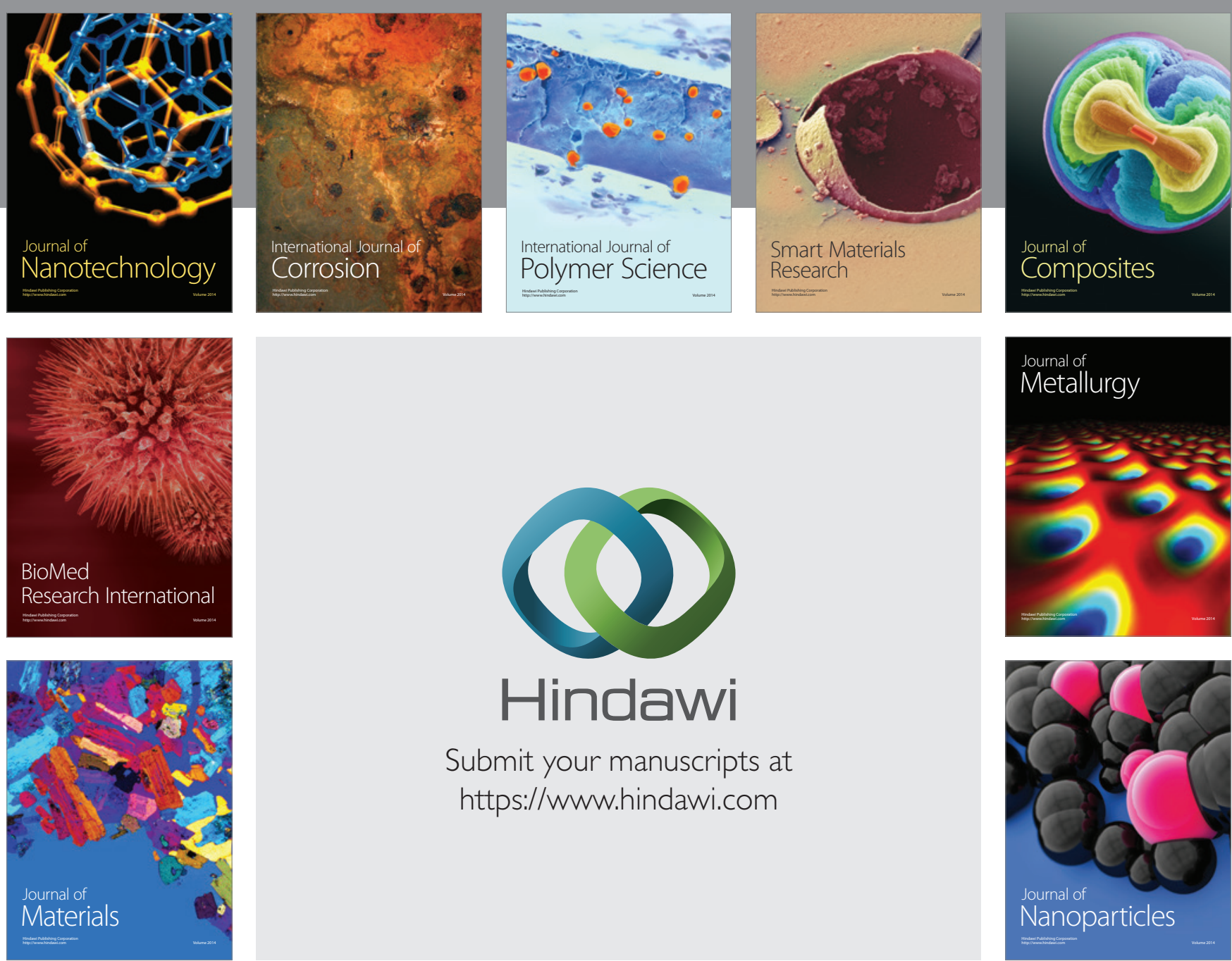

\section{Hindawi}

Submit your manuscripts at

https://www.hindawi.com

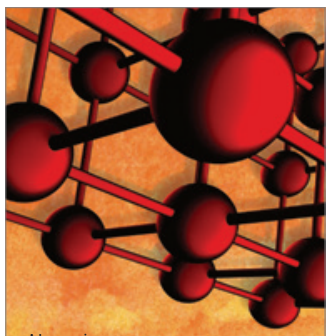

Materials Science and Engineering
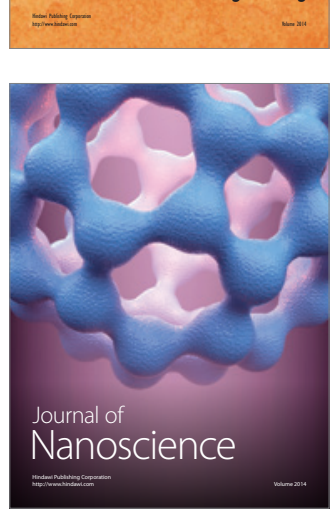
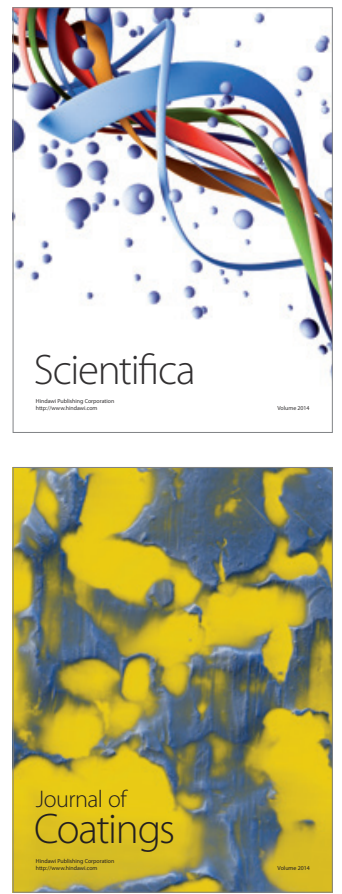
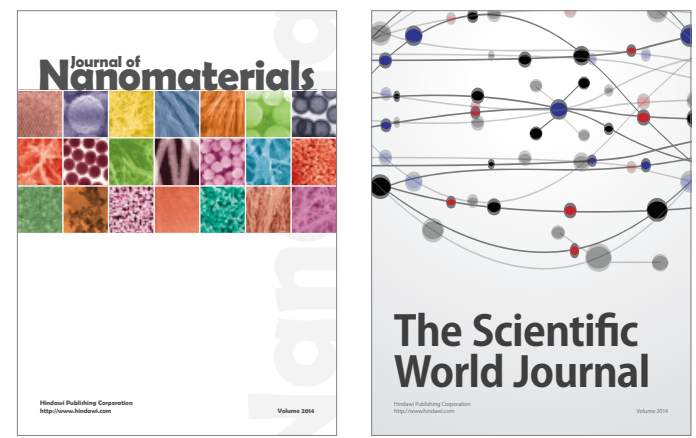

The Scientific World Journal
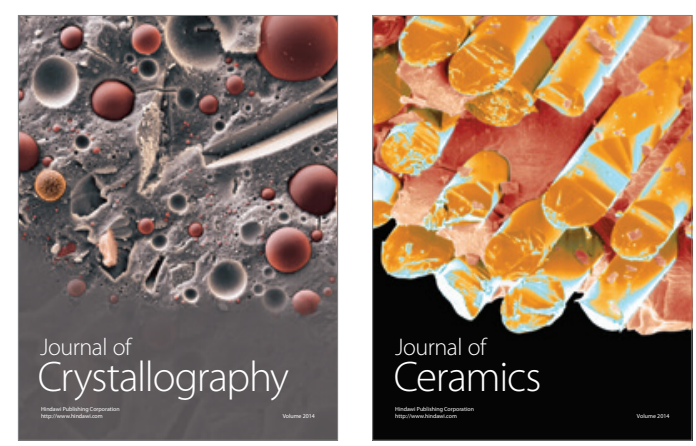
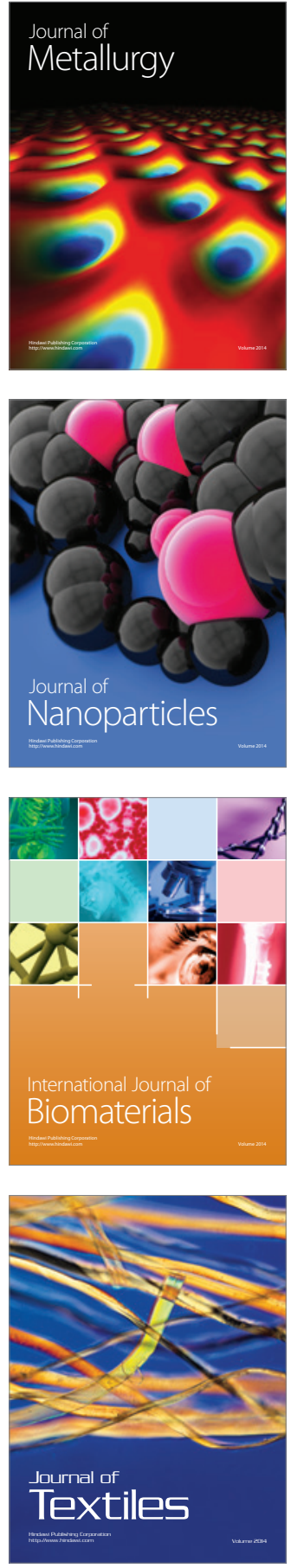